\title{
NON-INVASIVE TREATMENT OF UNUNITED FRACTURES OF THE TIBIA USING ELECTRICAL STIMULATION
}

\author{
W. G. DE HAAS, J. WATSON, D. M. MORRISON \\ From the Orthopaedic Research Laboratory \\ and the Department of Surgery, University of Calgary, Canada
}

\begin{abstract}
A non-invasive method of electrical stimulation of healing in ununited fractures of the tibia by pulsed magnetic fields has been evaluated. In a series of 17 patients all but two of the fractures united within 4 to 10 months, with an average time of just under six months. The method is sufficiently promising to merit further clinical investigation.
\end{abstract}

The application of electrical energy to fractures may stimulate their healing. The methods employed may be invasive, when electrodes are implanted directly into bone (Friedenberg, Harlow and Brighton 1971; Friedenberg et al. 1971; Cochran 1972; Lavine et al. 1972; Brighton et al. 1975, 1977; Becker, Spadaro and Marino 1977; Connolly, Hahn and Jardon 1977), or non-invasive, when current is generated across the fracture site by means of an externally applied pulsed magnetic field (Bassett, Pilla and Pawluk 1977; de Haas, Lazarovici and Morrison 1979).

Implanted electrodes can be accurately positioned and the flow of current controlled precisely. They may be used in the presence of metallic internal fixation (Brighton et al. 1977; Weigert and Werhahn 1977). However, an operation is required to insert and remove the electrodes with the possibility of infection, and they may dislodge or break. There might be harmful effects on the tissues from electrolysis at the sites of the electrodes. The passage of a small electric current between the electrodes has been found to stimulate bone formation. Most investigators have used direct (unidirectional) currents, but there is evidence to indicate that alternating (bidirectional) currents are equally effective (Iida et al. 1956; Wittebol 1970; Klapper and Stallard 1974).

Similar currents can be induced using an entirely non-invasive method. If a conducting material is placed in a changing magnetic field, a current will be induced which circulates around the axis of the magnetic field, the direction of circulation depending upon whether the magnetic field is rising or falling. Thus, if a pulsed magnetic field is placed transversely across the fracture site of a long bone an alternating current is induced, a portion of which may be expected to cross the fracture site. No operation is required, the technique is simple, and it may be used with infected fractures. The apparatus can be used repeatedly but it may be ineffective in the presence of metallic implants, and exact calculation of the current density induced at the fracture site is difficult, if not impossible.

Bassett, who pioneered the use of induced electric currents to stimulate fracture healing, demonstrated that the healing of osteotomies of the fibula in dogs could be accelerated by inducing a current across the site (Bassett, Pawluk and Pilla 1974a,b). More recently it has been shown that the initiation of fracture repair after osteotomy of the radius in rabbits may be enhanced by the external application of pulsed magnetic fields (de Haas et al. 1979). Bassett et al. (1977) also reported the clinical application of pulsed electromagnetic fields in the treatment of pseudoarthroses and ununited fractures, using air-cored coils, pulsed at a repetition rate of 75 hertz.

During the past six years, a clinical trial has been conducted at this centre on the use of magnetic fields, pulsed at a very low frequency (one hertz), in the treatment of fractures of the tibia complicated by non-union. Large iron-cored electromagnets were specially designed. Experience with a similar apparatus, adapted from this design, has been described by Watson and Downes $(1978,1979)$.

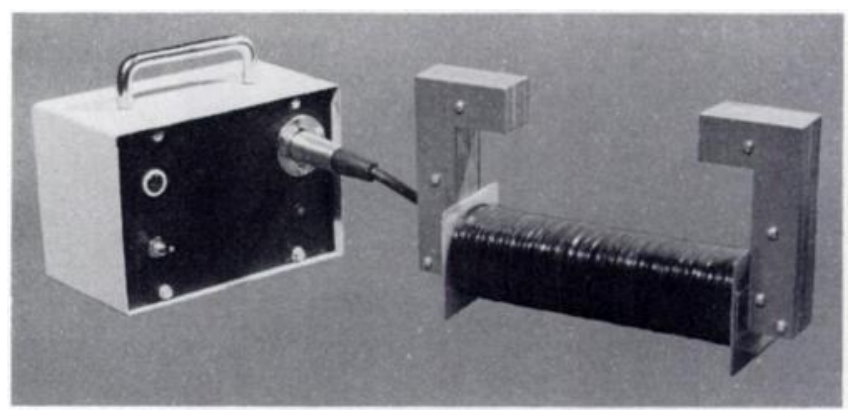

Fig. 1

Solid-core electromagnet with pulse driver.

W. G. de Haas, FRCS(C), \} Orthopaedic Research Laboratory,

D. M. Morrison, BSc.

J. Watson, PhD, Electrical Engineering Department. University of Wales, Swansea, Wales.

Requests for reprints should be sent to Dr W. G. de Haas, Professional Corporation, Suite 603, Medical Centre, 906-8th Avenue S. W., Calgary T2P 1 H9, Canada. 


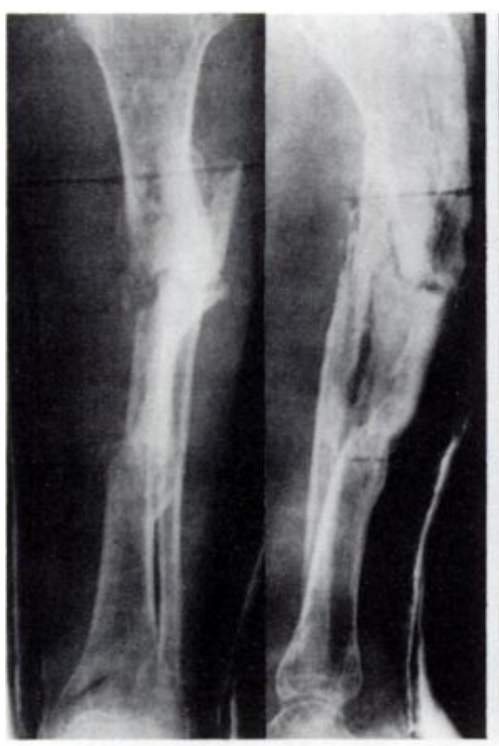

Fig. 2

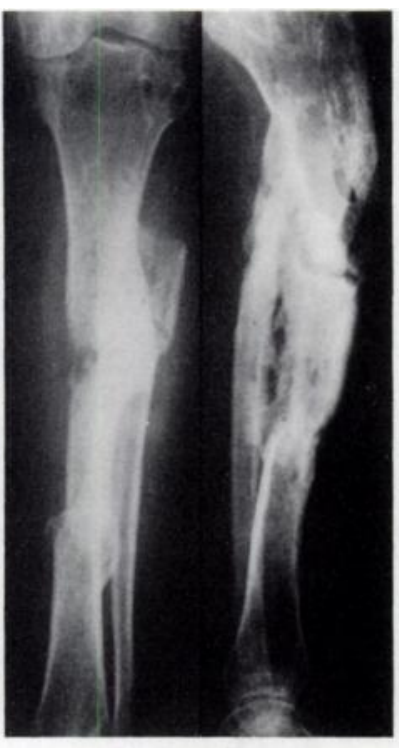

Fig. 3

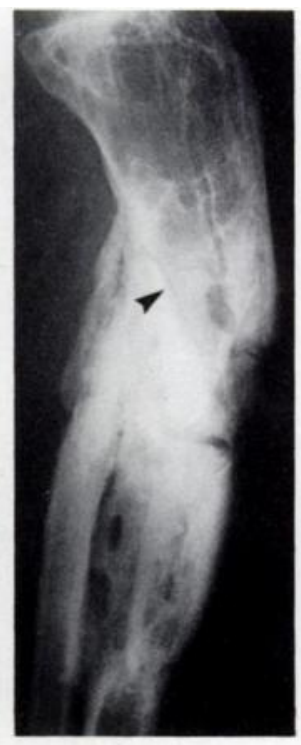

Fig. 4

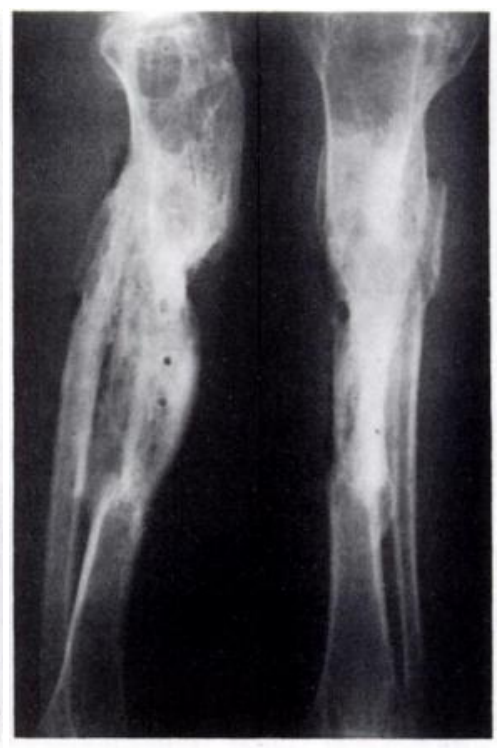

Fig. 5

Case 1. Figure 2-Ununited fracture before application of the pulsed magnetic field. Figure 3-Eight months later, the fracture has healed. Figure 4-Stress fracture proximal to the old fracture site. Figure 5-Solid union four years later.

\section{MATERIAL AND METHODS}

The apparatus consists of an electromagnet and a solid-state electronic drive unit (Fig. 1). The core of the electromagnet consists of a stack of soft iron laminae in a square $G$ configuration. The coil, which is wound around the bar of the $G$, is of 25 -gauge diameter insulated copper wire and is supplied with a pulsed current from the drive unit at a rate of one pulse per second. This rate cannot be exceeded because the high inductance presented by the electromagnet will prevent full build-up of the magnetic field strength in less than half a second. Although the driving voltage is a square wave, being derived from a multivibrator driving power transistor, the waveform of the current and hence of the magnetic field has an exponential rise and fall in which the full field strength is only just reached. Power is derived from a 50 -volt direct-current supply, making the unit electrically safe since it will not give any shock even if the coil is damaged sufficiently to expose the

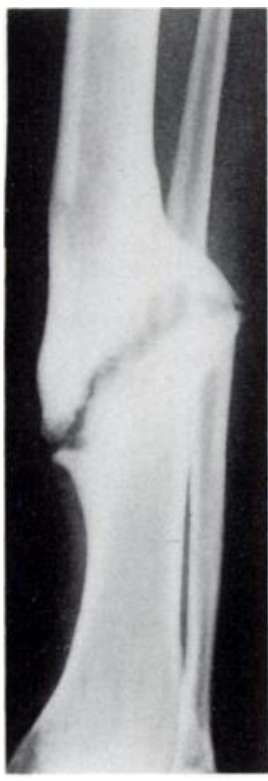

Fig. 6

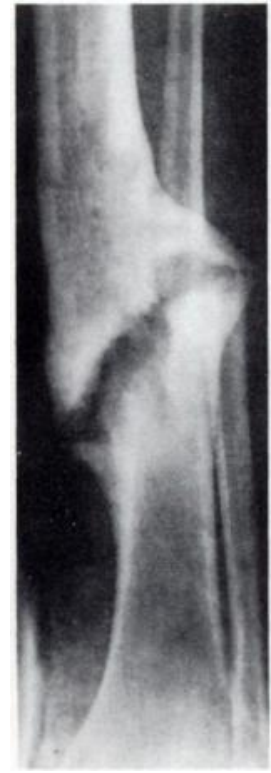

Fig. 7

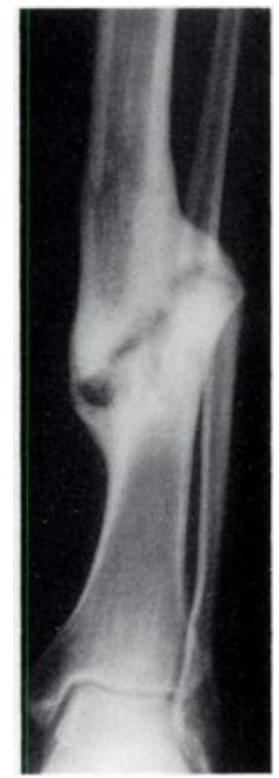

Fig. 8
Case 4. Figure 6-Established non-union three years after injury. Figure 7-Tomogram taken during treatment. Figure 8-Six months later, the fracture has united. windings. The two open pole faces of the electromagnet are square in cross-section, and are 115 millimetres apart.

The original assembly delivered a magnetic flux density of 150 gauss midway between the poles. A larger magnet was constructed with adjustable pole pieces, capable of delivering flux densities of 300 gauss or more at a point midway between them. Other models were designed to produce a field strength of 200 gauss at the midpoint between fixed pole pieces.

The electromagnet is placed across the cast at the level of the fracture site and the drive unit is plugged into a wall socket. The pulsed magnetic field is applied for $\mathbf{2 0}$ hours daily for periods ranging from four to eight weeks while the patient is confined to bed or sitting in a chair with the leg in a horizontal position. Treatment can be carried out at home. A pair of Textolite rectangles with U-shaped slots, which fit the ends of the electromagnet, are incorporated into the plaster cast on each side at the level of the fracture site. The magnet is placed in the slots and removed when not in use. The choice of a rate of one pulse per second is partly because of technical constraints, but also because it has been shown that the transfer function of bone as a piezo-electric transducer involves time constants comparable to those involved in walking (Levy 1974). Experiments on animals also suggest that a frequency of one hertz is optimal (de Haas et al. 1979).

After treatment is completed the fracture is immobilised in a cast until union has occurred, usually by four to six months.

Seventeen patients with established non-union of the tibia have been treated in this manner. Ten fractures were originally compound. Chronic osteomyelitis was present in six fractures when treatment began. The period from the time of injury until electrical stimulation was started varied from nine months to five years, averaging 22.2 months. Most patients had reached a stage where an initial or further operation was inevitable, and in three, whose fractures were complicated by osteomyelitis, amputation was under consideration.

Magnetic flux densities were employed ranging from 150 to 300 gauss as measured at the fracture site midway between the poles of the magnet (Table I). The impression was gained that fields of $\mathbf{3 0 0}$ gauss resulted in somewhat quicker bony union than did the weaker fields.

In the beginning of the trial patients were treated in hospital in order to see if the equipment functioned correctly, but later patients were admitted for only a day or two and, when familiar with the apparatus, were sent home to continue treatment.

All patients were immobilised in a long leg cast during treatment and until union was considered to be sound. 


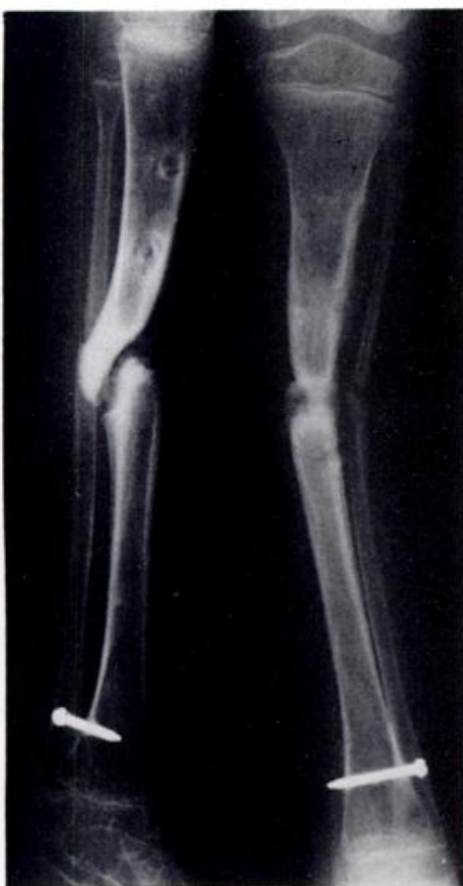

Fig. 9

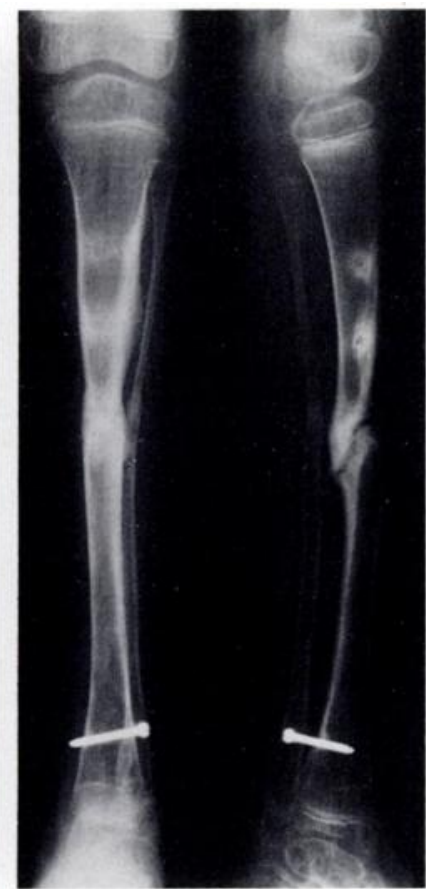

Fig. 10

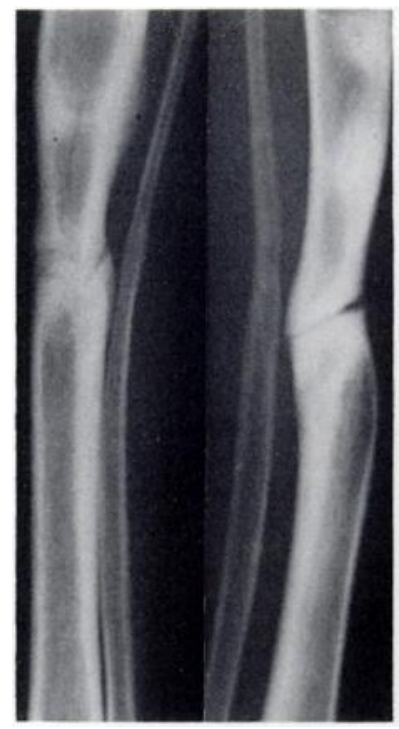

Fig. 11

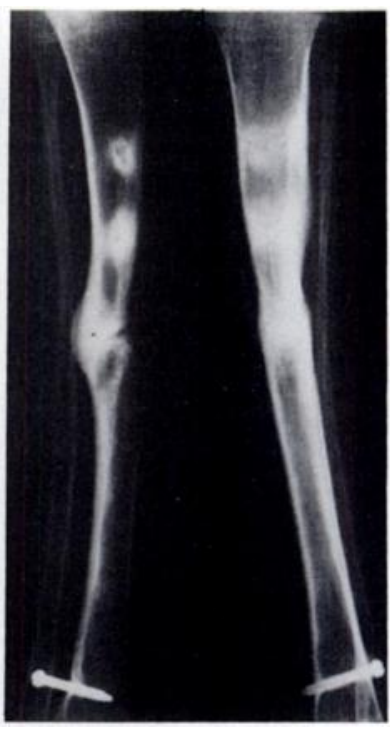

Fig. 12

Case 12. Figure 9-Non-union after leg lengthening. Figure 10Seven months after stimulation. Figure. $11-$ Fracture five months later. Note that the fracture line is in a different plane from the original fracture site. Figure $12-$ Fracture is united five months later.

\section{ILLUSTRATIVE CASE HISTORIES}

Case 1. A 53-year-old woman was first admitted to hospital on March 7,1969 , with a compound double fracture of the tibia and a fracture of the proximal fibula sustained in a motor accident. After debridement, the fractures were reduced without the use of internal fixation and the limb was immobilised in a long leg cast. Subsequently, she developed osteomyelitis which required saucerisation and closed irrigation in July 1969, and again two months later. In March 1970 there was no evidence of union at either of the fracture sites, and after a course of antibiotic therapy a posterolateral bone graft was performed at both fracture sites, using autogenous bone from the iliac crest. In July 1971 the distal fracture had united but a sinus was present at the upper fracture site, which remained ununited. In November 1971, through a window in the cast, further saucerisation was carried out followed by skin grafting. Finally in March 1972 there was evidence of bony union at both fracture sites, confirmed by tomograms. The cast was removed and the patient was fitted with a long leg brace. Two months later she developed pain over the proximal fracture site and movement was elicited at this level. In November 1972 a second bone graft was undertaken through a posterolateral approach. Eight months later there was no evidence of union, and in July 1973 a third bone graft was carried out at which time the proximal end of the fibula was excised. By the end of April 1974, nine months after this operation and five years after the original injury (Fig. 2), the proximal fracture remained ununited and the patient was advised to have the limb amputated, which she declined, requesting "electrical stimulation", about which she had read in a popular journal. At this time research was being conducted by the authors on the use of pulsed magnetic fields in the stimulation of fracture healing in rabbits, and an attempt was made to stimulate the site of the non-union using a pulsed magnetic field.

The field was applied continuously for a period of eight weeks during May and June 1974, except for a few hours each day when the patient was allowed out of bed. Radiographs taken at the end of June showed no convincing evidence of bone formation at the fracture site, and mobility was still present when the cast was changed. By the end of November 1974 new bone formation was visible at the fracture site. In January 1975 the cast was removed and the fracture was found to be stable and painless. Radiographs revealed further bone formation at the fracture site (Fig. 3). The patient was then mobilised with crutches, initially non-weight-bearing, but full weight was taken in March 1975.
The sinus had now healed. Unfortunately in August 1975 the patient developed a stress fracture of the tibia proximal to the site of her previous non-union (Fig. 4). This required further immobilisation in a cast but increasing angulation occurred and eventually internal fixation with a plate and screws was carried out in July 1976. The fracture then united satisfactorily; the cast was removed in November 1976 and weight-bearing established. For the past three years the patient has been taking full weight on the leg (Fig. 5).

Case 4. A 46-year-old man sustained a compound fracture of his left tibia and fibula on May 15, 1974, while at work, when a freezer fell on his leg. A long leg cast was applied, after debridement and reduction of the fracture. Two months later the patient removed the cast himself. He was put in a fresh cast but the fracture failed to unite. Therefore in March 1975 a sliding bone graft was performed, but the patient developed a draining sinus after this operation. In spite of antibiotic therapy the drainage continued and in March 1976 a sequestrectomy was performed. A further sequestrectomy was carried out in July 1976, after which the wound healed and remained dry. However, the fracture failed to unite and the patient was referred for treatment with a pulsed magnetic field in December 1976 (Fig. 6). The field was applied for a period of 24 days (Fig. 7). Six months later the fracture was clinically stable and there was radiological evidence of bony union at the fracture site (Fig. 8). The cast was removed and the patient commenced gradual weight-bearing, rapidly regaining a full range of movement at the knee and ankle. He has had no further problems since and has returned to work as a security guard.

Case 12. A 10-year-old boy was referred with an established non-union of the tibia (Fig. 9). He had undergone a leg lengthening operation on the tibia in April 1977 and had been immobilised in a cast since removal of the lengthening apparatus. Commencing in mid-March 1978, a pulsed magnetic field was applied for six weeks and immobilisation was continued for another six months. By November 1978 the fracture was found to be clinically stable and radiologically united (Fig. 10). Two months later, without permission, the youngster did some cross-country skiing. On April 5, 1979, he injured his leg when tackled in the school playground and sustained a transverse crack fracture which, although at the level of his previous fracture site, did not follow the plane of the original break (Fig. 11). This fracture healed spontaneously after immobilisation in a walking cast for four months (Fig. 12). He has been free of trouble since. 


\section{RESULTS}

All but two of the 17 fractures treated united solidly both clinically and radiologically (Table I). The duration of application of the magnetic field varied from three and a half weeks to 13 weeks. As a rule, a longer exposure time was required for fractures with active infection. The average time from the beginning of treatment in the magnetic field until the fracture had united was just under six months. The longest time was 10 months (Case 8) and the shortest time was four months (Cases 11 and 14).

Table I. Patients with established non-union treated in pulsed magnetic fields

\begin{tabular}{|c|c|c|c|c|c|c|c|c|c|c|}
\hline Case & $\begin{array}{c}\text { Age } \\
\text { (years) }\end{array}$ & Sex & $\begin{array}{l}\text { Type } \\
\text { of } \\
\text { injury }\end{array}$ & $\begin{array}{l}\text { Prior } \\
\text { treatment }\end{array}$ & $\begin{array}{l}\text { Time } \\
\text { since } \\
\text { fracture }\end{array}$ & $\begin{array}{l}\text { Presence of } \\
\text { osteomyelitis }\end{array}$ & $\begin{array}{c}\text { Duration } \\
\text { of magnetic } \\
\text { field application }\end{array}$ & Results & $\begin{array}{c}\text { Field } \\
\text { intensity }\end{array}$ & $\begin{array}{l}\text { Time to } \\
\text { union } \\
\text { (months) }\end{array}$ \\
\hline 1 & 53 & $\mathbf{F}$ & Compound & $\begin{array}{l}\text { Open reduction } \\
\text { Saucerisation } \\
\text { for infection } \times 3 \\
\text { Bone graft } \times 3\end{array}$ & 5 years & Yes & 10 weeks & Healed & 150 gauss & 8 \\
\hline 2 & 45 & $\mathbf{M}$ & Compound & $\begin{array}{l}\text { Open reduction } \\
\text { Plate } \\
\text { Bone graft } \times 2\end{array}$ & $21 / 4$ years & No & 3 weeks & Healed & 150 gauss & 7 \\
\hline 3 & 44 & $\mathbf{M}$ & Compound & $\begin{array}{l}\text { Open reduction } \\
\text { Saucerisation } \\
\text { Skin graft } \\
\text { Bone graft } \times 2 \\
\text { Pedicle skin graft } \times 2\end{array}$ & 3 years & Yes & 13 weeks & Healed & $\begin{array}{c}150 \text { gauss } \\
+ \\
300 \text { gauss }\end{array}$ & 6 \\
\hline 4 & 46 & $\mathbf{M}$ & Compound & $\begin{array}{l}\text { Open reduction } \\
\text { Bone graft } \\
\text { Sequestrectomy }\end{array}$ & 3 years & No & $31 / 2$ weeks & Healed & 300 gauss & 7 \\
\hline 5 & 29 & $\mathbf{M}$ & Closed & $\begin{array}{l}\text { Closed reduction } \\
\text { Cast } \\
\text { Immobilisation }\end{array}$ & 1 year & No & 6 weeks & Healed & 150 gauss & 5 \\
\hline 6 & 23 & $\mathbf{M}$ & Compound & $\begin{array}{l}\text { Closed reduction } \\
\text { Sequestrectomy } \\
\text { Fibular osteotomy }\end{array}$ & 3 years & No & 5 weeks & Healed & 150 gauss & 5 \\
\hline 7 & 51 & $\mathbf{M}$ & $\begin{array}{l}\text { Compound } \\
\text { comminuted }\end{array}$ & $\begin{array}{l}\text { Open reduction } \\
\text { Bone graft }\end{array}$ & 11 months & Yes & 6 weeks & Failed & 150 gauss & - \\
\hline 8 & 24 & $\mathbf{F}$ & Closed & $\begin{array}{l}\text { Manipulative } \\
\text { reduction }\end{array}$ & 1 year & No & $\begin{array}{c}6 \text { weeks } \\
+ \\
4 \text { weeks }\end{array}$ & Healed & $\begin{array}{c}150 \text { gauss } \\
+ \\
300 \text { gauss }\end{array}$ & 10 \\
\hline 9 & 24 & $\mathbf{M}$ & $\begin{array}{l}\text { Osteotomy } \\
\text { tibia }\end{array}$ & $\begin{array}{l}\text { Previous ankle fusion } \\
\text { Sequestrectomy of } \\
\text { tibia } \\
\text { Bone graft to tibia }\end{array}$ & 18 months & No & 6 weeks & Healed & 200 gauss & 6 \\
\hline 10 & 45 & $\mathbf{M}$ & $\begin{array}{l}\text { Compound } \\
\text { comminuted } \\
\text { Distal } \\
\text { tibia }\end{array}$ & $\begin{array}{l}\text { Ankle fusion } \\
\text { Bone graft to tibia }\end{array}$ & 3 years & No & $\begin{array}{c}6 \text { weeks } \\
+ \\
6 \text { weeks }\end{array}$ & $\begin{array}{l}\text { Failed } \\
\text { Failed }\end{array}$ & $\begin{array}{l}150 \text { gauss } \\
300 \text { gauss }\end{array}$ & - \\
\hline 11 & 19 & $\mathbf{M}$ & Closed & $\begin{array}{l}\text { Compression plate } \\
\text { (with infection) } \\
\text { Debridement } \\
\text { Sequestrectomy } \\
\text { Skin graft } \times 2\end{array}$ & 1 year & Yes & 6 weeks & Healed & 300 gauss & 4 \\
\hline 12 & 10 & $\mathbf{M}$ & & Lengthening of tibia & 1 year & No & 6 weeks & Healed & 200 gauss & 7 \\
\hline 13 & 48 & $\mathbf{F}$ & Compound & Debridement & 9 months & No & 6 weeks & Healed & 300 gauss & 5 \\
\hline 14 & 30 & $\mathbf{M}$ & Compound & $\begin{array}{l}\text { Open reduction } \\
\text { Bone graft } \\
\text { Removal of screws }\end{array}$ & 9 months & No & 6 weeks & Healed & 300 gauss & 4 \\
\hline 15 & 26 & $\mathbf{M}$ & Compound & $\begin{array}{l}\text { Open reduction } \\
\text { with screws } \\
\text { Bone graft }\end{array}$ & 19 months & No & 6 weeks & Healed & 300 gauss & $41 / 2$ \\
\hline 16 & 25 & $\mathbf{M}$ & Closed & $\begin{array}{l}\text { Open reduction } \\
\text { with bone graft }\end{array}$ & 15 months & Yes & 6 weeks & Healed & 200 gauss & 5 \\
\hline 17 & 35 & $\mathbf{M}$ & Closed & $\begin{array}{l}\text { Open reduction } \\
\text { Sequestrectomy }\end{array}$ & 18 months & Yes & 6 weeks & Healed & 200 gauss & 6 \\
\hline
\end{tabular}


Table II. Comparative study

\begin{tabular}{|l|l|l|}
\hline & Conventionally treated group & Magnetic stimulation group \\
\hline $\begin{array}{l}\text { Number of fractures ununited } \\
\text { after nine months }\end{array}$ & 23 & 17 \\
Closed fractures & 6 & 7 \\
Compound & 17 & 10 \\
Time since fracture & 9 months & 9 to 60 months (average 22.2 months) \\
Percentage with active sepsis & 39 per cent & 35 per cent \\
Time to union & 1 to 39 months & 4 to 10 months \\
Average & 10.7 months & 5.9 months \\
Percentage healed & 82.5 per cent & 88.2 per cent \\
Failed & 4 patients (17.5 per cent) & 2 patients (11.8 per cent) \\
& All amputated & Bone grafted \\
\hline
\end{tabular}

Two patients failed to respond to treatment.

Case 7. This patient had a comminuted compound fracture of the proximal tibia which remained ununited after six weeks of treatment and a further six months of immobilisation in a long leg cast. His referring surgeon elected to carry out a bone graft at this stage. Case 10. This patient had a comminuted fracture of the distal tibia and was treated by bone grafting and fusion of the ankle, which failed. He was treated in a pulsed magnetic field for six weeks and six months later the fracture of the tibia had united, but there was still movement at the level of the arthrodesis of the ankle. He was kept in a long leg cast and the pulsed magnetic field was then centred at the ankle and stimulation continued for a further six weeks. Six months later the ankle was clinically stable and radiographs appeared to show healing, but after weight-bearing he developed pain and movement was present at the ankle. The fusion was then revised.

Both patients had a satisfactory result from their operations.

In four out of the six patients with infected fractures union was achieved and the wounds healed without subsequent breakdown. In two patients the fractures healed but continuing drainage necessitated later sequestrectomy.

The tibia refractured in four patients. All had undisplaced stress fractures which occurred through the original fracture site in two patients and adjacent to the original fracture in the others. These fresh fractures all united and no other complications were encountered.

There was no noticeable difference between the patients treated in hospital and those treated at home except in Case 8. This young woman had sustained a closed fracture in a motor accident one year before treatment was started. She was treated at home for six weeks but the fracture remained ununited five months later. Litigation was settled at this time and she was readmitted to hospital for stimulation under supervision for four weeks. The fracture was united four months later.

\section{DISCUSSION}

This treatment is simple and it appears to be safe. In the absence of a control series, and particularly with so few patients, the effectiveness of the treatment may be questioned. However, it seems unlikely that these fractures would have healed had they been immobilised without applying the pulsed fields, since all had an established non-union and had previously been continuously immobilised in a cast for between nine months and five years, with an average of 22.2 months. After treatment all but two of the patients achieved solid union in an average time of just under six months.

Since a double-blind trial was impracticable, a comparative study of displaced fractures of the shaft of the tibia was undertaken with cases selected from a previous survey (Macnab and de Haas 1974). Only fractures which had failed to unite by nine months were included. There were 23 such fractures (six closed and 17 compound), 18 of which had been treated by operation with various types of bone graft. Table II shows that the time to union of the magnetically treated patients was much shorter than for the control group, although some of the fractures included in the control series were almost united by nine months, which explains the wide range in time of healing of between one and 39 months in the latter series. All the fractures in the comparative study which failed to unite necessitated amputation whereas the two fractures which did not unite after treatment by pulsed magnetic fields healed after subsequent bone grafts.

Another study (Nicoll 1964) in which 705 cases of tibial fractures were studied lends itself for comparison to our experimental results. Out of the 674 fractures which were treated conservatively, 51 had failed to unite after nine months, and of these 35 went on to established non-union, giving an incidence of non-union of 70 per cent in fractures which had not healed by that time. In our series only 13 per cent of such fractures failed to unite after treatment in pulsed magnetic fields.

The mechanism whereby a pulsed magnetic field might stimulate fracture healing remains obscure. External callus formation is not conspicuous and examination of the radiographs suggests that some 


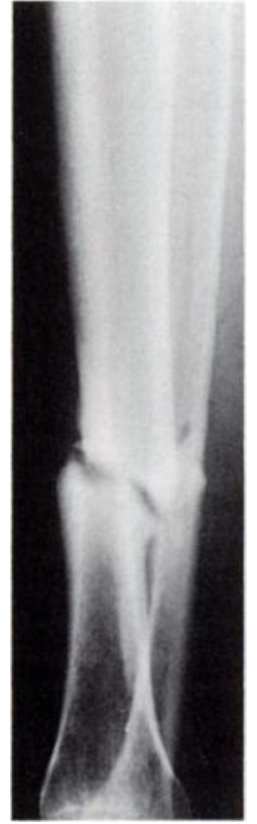

Fig. 13

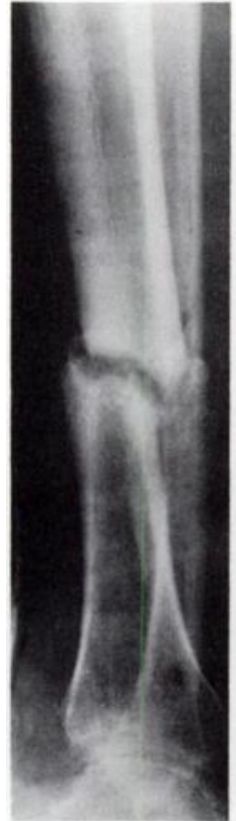

Fig. 14

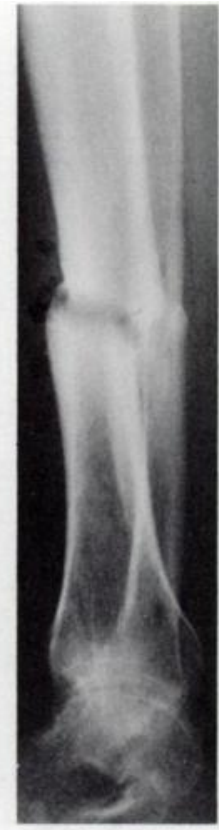

Fig. 15

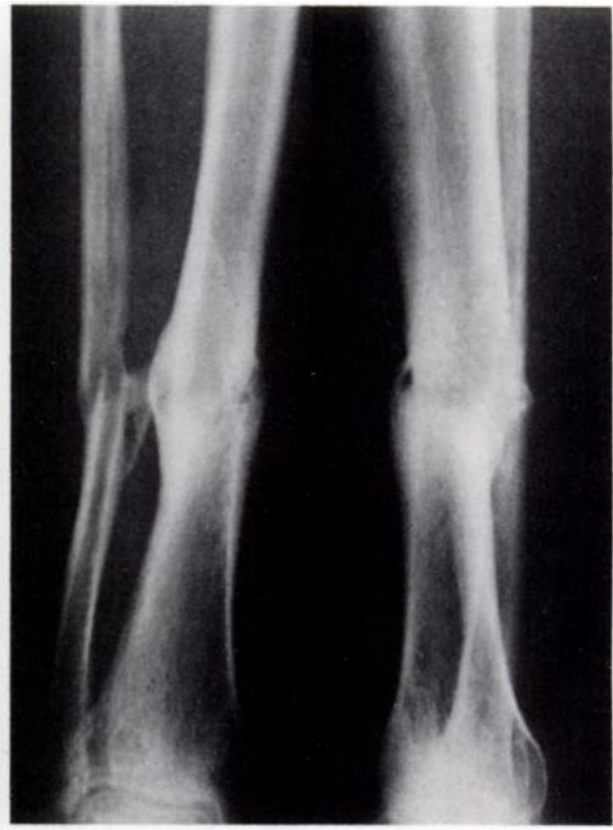

Fig. 16

Case 5. Figure 13-Ununited fracture one year after injury. Note sclerosis at the fracture site. Figure 14-At completion of treatment six weeks later, demineralisation near the fracture site is evident, and early callus formation is present. Figure 15-Five months after treatment was started, the fracture has united. Figure 16-Eleven months after treatment commenced.

revascularisation occurs at the fracture site, reducing the density of the bone ends. This is followed by very gradual interfragmentary callus formation, which eventually bridges the fracture site (Figs 13 to 16 ).
Our results are encouraging and this form of treatment warrants further investigation. An extensive study is now being conducted in various centres in Canada.

The authors are indebted to $\mathrm{Mr} \mathrm{M}$. A. Lazarovici for designing some of the electromagnets, to $\mathrm{Mr} \mathrm{P}$. Walding and Mr W. Morrison of the Department of Electronics, Foothills Hospital, Calgary, for building the drive units for these magnets, and to Mr R. Long, for assembly and maintenance. The authors also thank Mr A. Nordquist of the Electrical Engineering Department, University of Calgary, for building the first complete assembly. Case 1 was presented at the COA meeting in Ottawa in 1975 and at the SICOT meeting in Copenhagen in 1975.

\section{REFERENCES}

Bassett CAL, Pawluk RJ, Pilla AA. Augmentation of bone repair by inductively coupled electromagnetic field. Science 1974a;184:575-7.

Bassett CAL, Pawluk RJ, Pilla AA. Acceleration of fracture repair by electromagnetic fields: a surgically noninvasive method. Ann NY Acad Sci $1974 b ; 238: 242-61$.

Bassett CAL, Pilla AA, Pawluk RJ. A non-operative salvage of surgically-resistant pseudoarthrosis and non-unions by pulsing electromagnetic fields. Clin Orthop 1977;124:128-43.

Becker RO, Spadaro, JA, Marino AA. Clinical experiences with low intensity direct current stimulation of bone growth. Clin Orthop 1977;124:75-83.

Brighton CT, Friedenberg ZB, Zemsky LM, Pollis PR. Direct-current stimulation of non-union and congenital pseudoarthrosis. J Bone Joint Surg $[$ Am $]$ 1975;57-A:368-77.

Brighton CT, Friedenberg ZB, Mitchell EI, Booth RE. Treatment of nonunion with constant direct current. Clin Orthop 1977;124:106-23.

Cochran G Van B. Experimental methods of stimulation of bone healing by means of electrical energy. Bull NY Acad Med 1972;48:899-911.

Connolly JF, Hahn H, Jardon OM. The electrical enhancement of periosteal proliferation in normal and delayed fracture healing. Clin Orthop 1977;124:97-105.

de Haas WG, Lazarovici MA, Morrison DM. The effect of low frequency magnetic fields on the healing of the osteotomized rabbit radius. Clin Orthop 1979;145:245-51.

Friedenberg ZB, Harlow MC, Brighton CT. Healing of nonunion of the medial malleolus by means of direct current: a case report. $J$ Trauma 1971;11:883-5.

Friedenberg ZB, Roberts PG Jr, Didizian NH, Brighton CT. Stimulation of fracture healing by direct current in the rabbit fibula. J Bone Joint Surg $[A m] 1971 ; 53-A: 1400-8$

lida H, Ko S, Miyashita Y, Sawada S, Meada M, Nagayama H, Kawai A, Kitmura S. On electrical callus produced by an altering current. Journal of Kyoto Prefectural University of Medicine 1956;60:561.

Klapper L, Stallard RE. Mechanism of electrical stimulation of bone formation. Ann NY Acad Sci 1974;238:530-9.

Lavine LS, Lustrin I, Shamos MH, Rinaldi RA, Libof AR. Electrical enhancement of bone healing. Science 1972;175:1118-21.

Levy DD. A pulsed electrical stimulation technique for inducing bone growth. Ann NY Acad Sci 1974;238:478-89.

Macnab I, de Haas WG. The role of the periosteal blood supply in the healing of fractures of the tibia. Clin Orthop 1974;105:27-33.

Nicoll EA. Fractures of the tibial shaft. J Bone Joint Surg [Br] 1964;46-B:373-87.

Watson J, Downes EM. The application of pulsed magnetic fields to the stimulation of bone healing in humans. Jap J Appl Phys 1978;17:215-8.

Watson J, Downes EM. Clinical aspects of the stimulation of bone healing using electrical phenomena. Med Biol Eng Comput 1979;17:161-9.

Weigert M, Werhahn C. The influence of electric potentials on plated bones. Clin Orthop 1977;124:20-30.

Wittebol P. Stimulation of non-epiphyseal bone growth. Calcif Tissue Res 1970;4 Suppl:122. 